\title{
Correction to: Using FFF and Topology Optimisation to Increase Crushing Strength in Equestrian Helmets
}

Shwe Soe, Michael Robinson, Khaled Giasin, Rhosslyn Adams, Tony Palkowski, and Peter Theobald

\section{Correction to:}

Chapter "Using FFF and Topology Optimisation

to Increase Crushing Strength in Equestrian Helmets" in:

S. G. Scholz et al. (eds.), Sustainable Design

and Manufacturing 2020, Smart Innovation,

Systems and Technologies 200,

https://doi.org/10.1007/978-981-15-8131-1_33

In the original version of the book, the author name has been updated from "Khaled Gaisin" to "Khaled Giasin" in the Chapter "Using FFF and topology optimisation to increase crushing strength in equestrian helmets". The chapter and book have been updated with the changes. 